\title{
A INCONSTITUCIONALIDADE DA SUSPENSÃO DO SERVIÇO DE ENERGIA ELÉTRICA DE CONSUMIDOR HIPERVULNERÁVEL EM FACE DO PRINCÍPIO DA DIGNIDADE DA PESSOA HUMANA
}

MARIANA RODRIGUES LOPES MORAES 


\title{
A INCONSTITUCIONALIDADE DA SUSPENSÃO DO SERVIÇO DE ENERGIA ELÉTRICA DE CONSUMIDOR HIPERVULNERÁVEL EM FACE DO PRINCÍPIO DA DIGNIDADE DA PESSOA HUMANA
}

\author{
Mariana Rodrigues Lopes Moraes ${ }^{1}$
}

\section{RESUMO}

O presente artigo tem o escopo de analisar a inconstitucionalidade da suspensão de energia elétrica em face da dignidade da pessoa humana, tendo em vista consumidor em estado de miserabilidade. O debate ocorre, uma vez que, de um lado, encontra-se o Código de Defesa do Consumidor, com seu sistema protetivo, o serviço público velado pelo caráter de essencialidade, bem como a Constituição da República Federativa Brasileira e o princípio da dignidade da pessoa humana como fundamento do Estado democrático de direito. De outro, as concessionárias e seus direitos diante da inadimplência do consumidor, o amparo trazido pela Lei $\mathrm{n}^{\mathrm{o}} 8.987$, de 1995 , e pela resolução da ANEEL n ${ }^{\circ} 414$, de 2010.

Palavras-chave: Energia elétrica. Serviço público. Dignidade da pessoa humana.

\begin{abstract}
The present work has the scope to examine the unconstitutionality of the suspension of electricity in the face of human dignity, with a view the consumer in a state of misery. The debate occurs because on one side you will find the Code of Consumer Protection, noted this vulnerability, veiled by the public service character of essentiality, as well as the constitution of the federative republic of Brazil and the principle of dignity of the human person as the Foundation of the

1 Assessora do juiz de Direito Presidente dos Conselhos da Justiça Militar do Estado do Tocantins. Graduada em Direito pela Universidade Federal do Tocantins (UFT). Pós-Graduanda Lato Sensu em Criminologia e Ciências Criminais na Escola Superior da Magistratura Tocantinense (ESMAT). E-mail: mari.marimoraes@gmail.com.
\end{abstract}


democratic State of law. On the other hand, the concessionaires and their rights in the face of consumer delinquencies, the support brought by Law 8.987/95 and by ANEEL Resolution n. 414/10.

Keywords: Electrical energy. Public service. Dignity of the human person

\section{INTRODUÇÃO}

A demasiada desigualdade social sofrida pelo Brasil tem como uma das fontes geradoras a má distribuição de renda e, consequentemente, parcela da população encontra-se em estado de miserabilidade, não possuindo patrimônio mínimo existencial, nem mesmo condições financeiras de arcar com as tarifas dos serviços públicos, como, por exemplo, o de energia elétrica.

A Constituição da República Federativa do Brasil de 1988, em seu artigo $1^{\circ}$, inciso III, trata do princípio da dignidade da pessoa humana como um dos fundamentos da República, no qual todo cidadão tem direito à vida digna, sendo-lhe assegurado o devido respeito, posto a dignidade ser uma forma de valorização do ser humano.

Além disso, os serviços essenciais estão balizados pelo princípio da continuidade, caracterizados como essenciais por serem indispensáveis para a manutenção da vida e dos direitos. Logo, fica clara a impossibilidade de sua interrupção por acometer a qualidade de vida e saúde, não sendo concebível viver dignamente sem energia elétrica.

Destarte, o presente estudo tem como objeto indivíduos 
pertencentes a um grupo de inadimplentes, os quais se encontram em estado de miserabilidade, não possuindo patrimônio mínimo vital.

Diante disso, indaga-se: como garantir vida digna se o não atendimento às necessidades vitais atenta contra a própria condição de ser humano? Levando em consideração o princípio da dignidade da pessoa humana, é constitucional a suspensão do fornecimento da energia elétrica em razão da inadimplência por hipervulneráveis?

O objetivo é analisar a inconstitucionalidade da suspensão do fornecimento de energia elétrica em face do princípio da dignidade da pessoa humana; estudar os fundamentos do direito à dignidade como garantia constitucional ressaltado o caráter de essencialidade do fornecimento de energia elétrica e confrontá-lo com a descaracterização do princípio da continuidade diante da inadimplência do usuário - consumidor pessoa física miserável.

Para tanto, adotou-se o método indutivo, partindo-se de um caso particular, qual seja, daqueles hipossuficientes economicamente, para se chegar a uma conclusão geral, bem como procedimento descritivo e bibliográfico, ao modo com que foi desenvolvida por procedimento de investigação e captação de dados da literatura nacional, passando pelo Direito Administrativo, Constitucional e, mormente, pelo Direito do Consumidor, analisando-se o problema principal e descrevendo suas vertentes com intuito de auferir os objetivos expostos.

Há alguns anos o Estado era o único responsável pela prestação dos serviços públicos essenciais à sociedade; entretanto, a incapacidade de atender com eficiência às crescentes demandas 
e de acompanhar com infraestrutura a expansão dos serviços levou à privatização. Assim, ao delegar à iniciativa privada a tarefa de prestar os serviços essenciais, ficou reservado ao Poder Público o dever de fiscalizar.

Surge a partir dessas transformações uma nata relação de consumo, em que o fornecedor visa ao lucro a ser obtido e seus interesses particulares, e o consumidor, diante da ausência do poder de escolha em contratar ou não o serviço de energia elétrica dada sua essencialidade, é a parte mais vulnerável, ficando à mercê do fornecido pela concessionária.

O tema é conflitante, tendo em vista de um lado a Constituição da República Federativa do Brasil a versar sobre o princípio da dignidade da pessoa humana, bem como o Código de Defesa do Consumidor a expor o serviço público essencial pela análise do princípio da continuidade. Além disso, devemse destacar o consumidor, a relação de consumo e seu sistema protetivo.

Por outro lado, estão as concessionárias e seus direitos diante da inadimplência do consumidor e, também, o amparo trazido pela resolução da Agência Nacional de Energia Elétrica (ANEEL), nº 414, de 2010, que não caracteriza como descontinuidade do serviço a sua interrupção, após aviso prévio, quando for motivada por inadimplência do usuário, considerado o interesse da coletividade.

Nesse diapasão, é importante a análise da Lei n ${ }^{\circ} 8.987$, de 1995, a qual dispõe sobre o regime de concessão e permissão da prestação de serviços públicos, uma vez que a suspensão do serviço de energia elétrica conflita com o princípio da 
continuidade.

Diante disso, ressalta-se o caráter da essencialidade do fornecimento de energia elétrica e, ao mesmo tempo, o descumprimento das obrigações contratuais por parte do consumidor. Sendo assim, analisar-se-á o entendimento jurisprudencial quanto à legalidade ou ilegalidade do corte de energia elétrica de todos os consumidores, em particular dos caracterizados pela hipervulnerabilidade.

\section{O PRINCÍPIO DA DIGNIDADE DA PESSOA HUMANA E A RELAÇÃO COM A SUSPENSÃO DO FORNECIMENTO DE ENERGIA ELÉTRICA}

O princípio da dignidade da pessoa humana é direito fundamental garantido constitucionalmente. Importante frisar que a dignidade é inerente ao ser humano, não podendo ser, portanto, renunciável ou alienável. Além disso, é alicerce de todo ordenamento jurídico constitucional e o último refúgio dos direitos individuais, e geradora do desenvolvimento do Estado Democrático de Direito.

Existem princípios que, apesar de integralizarem os direitos fundamentais, não estão expressos na Carta Magna, como, por exemplo, o direito ao mínimo existencial. Nesse sentido, Robert Alexy elucida: "As normas de direito fundamental podem, portanto, ser divididas em dois grupos: as normas de direito fundamental estabelecidas diretamente pelo texto constitucional e as normas de direito fundamental 
atribuídas." (2011, p. 73).

Sendo assim, correspondente à concepção de dignidade humana é que se explora a ideia de mínimo existencial, já que a exiguidade de suprimento às necessidades substanciais afronta a dignidade humana. Em outros termos, o mínimo existencial legitima-se ao entendimento de ter garantido o mínimo para uma vida com dignidade.

Nota-se o desvelo do constituinte originário de 1988, ao estabelecer a dignidade da pessoa humana como fundamento do Estado democrático de direito. Este é o princípio maior, basilar ao ordenamento jurídico, sem o qual o Estado perde sua própria razão de existir, já que o princípio da dignidade da pessoa humana dá diretriz para harmonização de todos os demais princípios, essa prerrogativa é o valor absoluto, supremo (DI LORENZO, 2009, p.53,).

Podem ser salientados dois sustentáculos da dignidade da pessoa humana, são eles: a liberdade e a igualdade. Aquela permite ao homem exercer seus direitos existenciais de forma plena, pois o exercício da liberdade em toda sua plenitude pressupõe a existência de condições mínima (ANDRADE, 2008, p.6). Dessa maneira, fica claro que o exercício da liberdade como fundamento da dignidade demonstra não ser possível viver - de forma livre e, consequentemente, digna - se não for proporcionado ao homem acesso aos serviços públicos essenciais, como educação, saúde, alimentação, saneamento básico, e, também, energia elétrica, entre outros tantos valiosos para uma sobrevivência mínima.

Ademais, a dignidade conjectura a ideia de igualdade 
entre os indivíduos, pois todos possuem necessidades básicas e carecem de respeito pelo Estado e entre a própria comunidade. $\mathrm{O}$ fato de todo ser humano ter, inerente à sua condição, dignidade, significa o merecimento de igual respeito a todos os indivíduos, pois possuidores de igual importância intrínseca. A finalidade desta resume-se, então, a garantir o respeito, por meio de um comportamento fraterno, sem discriminação. Caso não seja assegurada a liberdade e a igualdade, não se pode viver com dignidade.

A Constituição da República Federativa Brasileira em face de seus princípios fundamentais, mormente, a dignidade da pessoa humana, abre espaço para o debate e a análise da (i)legalidade quanto à suspensão do fornecimento de energia elétrica. Destaca-se ser o objeto do presente estudo referente a indivíduos inadimplentes que se encontram em estado de miserabilidade.

Não se pode negar a imprescindibilidade do fornecimento de energia elétrica, tanto que esta fora elencada no ordenamento jurídico pátrio como um dos serviços essenciais, no artigo 10 da Lei ${ }^{0}$ 7.783, de 1989. Assim, ao registrar a não garantia a esse grupo de cidadãos de um mínimo existencial, e considerandose a violação da própria condição de ser humano quando não se veem atendidas as necessidades vitais, indaga-se, se fundamentadas no princípio da dignidade da pessoa humana, a respeito da constitucionalidade do corte de energia elétrica.

$\mathrm{O}$ direito à dignidade está relacionado a usufruir de condições mínimas de sobrevivência e vida saudável, e ao suspender esse serviço essencial evidente é o confronto à 
dignidade da pessoa humana. Seria deplorável admitir que esse princípio seja renunciável em face de um direito de crédito.

Em consonância, analisa Sarlet:

O que se percebe, em última análise, é que onde não houver respeito pela vida e pela integridade física e moral do ser humano, onde as condições mínimas para uma existência digna não forem asseguradas, onde não houver limitação do poder, enfim, onde a liberdade e a autonomia, a igualdade (em direitos e dignidade) e os direitos fundamentais não forem reconhecidos e minimamente assegurados, não haverá espaço para a dignidade da pessoa humana e esta (a pessoa), por sua vez, poderá não passar de mero objeto de arbítrio e injustiças. (SARLET, 2011, p. 71)

Após ter fundamentado o princípio da dignidade da pessoa humana, o contemplado como instrumento fundamental do Estado Democrático de Direito e observado a igualdade e a liberdade como parte de sua estrutura, bem como problematizado sua incompatibilidade com o corte de energia elétrica, é necessário identificar seu conceito estudando-o em três aspectos, quais sejam: filosófico, sociológico e jurídico.

\subsection{Aspecto filosófico, sociológico e jurídico do princípio da dignidade da pessoa humana.}

A dignidade da pessoa humana, com o advento do iluminismo, começa a se desenvolver pela ótica da filosofia; aqui, o homem passa a ser o centro, contrapondo-se à visão teocêntrica 
dominante na Europa desde a Idade Média. Nessa esteira, é de Immanuel Kant - representante do iluminismo alemão - a concepção prevalecente no pensamento filosófico atual, em que reafirma o papel da racionalidade na ética, uma vez que um dos problemas filosóficos fundamentais seria relativo à ação humana e aos problemas morais com ela envolvidos (MARTINS, 2012, p. 25). Para o filósofo, a ideia de autonomia e dignidade está ligada, isso porque apenas os seres racionais, por serem dotados de autonomia - liberdade para dar a si mesmo sua própria lei - e por essa característica ser de natureza racional, possuem dignidade.

O filósofo trata do homem, ser racional, como um fim em si mesmo, e exatamente por dispor de tal circunstância deve possuir dignidade e ser respeitado. Em contrapartida, explana a respeito dos seres irracionais elucidando que sua existência depende da vontade da natureza, ou seja, diferente do ser humano que é um fim em si mesmo, os irracionais são meios (por esse motivo denominado de coisa), e por tal característica possuem valor relativo (KANT, 2009, p. 256). Dessa forma, observa-se que o homem, justamente pelo fato de ser pessoa, ser racional, tem dignidade. Destarte, segue a ensinar Kant:

No reino dos fins tudo tem ou bem um preço ou bem uma dignidade. $\mathrm{O}$ que tem preço, em seu lugar também se pode pôr outra coisa, enquanto equivalente; mas o que se eleva acima de todo preço, não permitindo qualquer equivalente, tem uma dignidade. (KANT, 2009, p. 265)

Nessa esteira, nota-se que todos os seres possuem um 
valor, todavia os seres irracionais são detentores do chamado valor relativo, compreendido como preço, e, portanto, podem ser substituídos por outra coisa de equivalente. Já a dignidade está acima de qualquer preço, sendo, por conseguinte, inerente a cada pessoa. Logo, a pessoa humana como ser racional e também não substituível, possui dignidade.

Com o decorrer do tempo, a dignidade humana passou a ter um escopo político, sendo que o estado e a própria sociedade deveriam possibilitá-la. Jean-Paul Sartre, representante do existencialismo, influenciado pelas ideias de Marxismo, desenvolve sua concepção, o que "acaba também por ser uma síntese dessa noção (marxista) dignidade da pessoa humana e da maneira de ver o homem no contexto do existencialismo" (MARTINS, 2012, p. 29).

Essa corrente negou a concepção religiosa ou metafísica da dignidade da pessoa humana, renegando a dignidade inata ao ser humano. Flademir Martins ensina que:

Para Sartre o homem primeiro existe antes de ter sua essência, ou, em outras palavras, 'a existência precede a essência'. Isso significa que o homem existe para si e que não foi criado a partir de uma essência anterior(como, por exemplo, uma essência divina). Assim não haveria uma natureza humana. E exatamente porque a existência precede a essência é que o homem não está sujeito a um determinismo. Ao contrario, seu futuro está inteiramente por construir. (MARTINS, 2012, p.30)

Destarte, nessa linha de pensamento, a ideia de que a 
existência ainda está por construir é o que embasa a dignidade humana. $\mathrm{O}$ homem não possui uma existência predeterminada (já que sua existência ainda está por construir). Sendo assim, percebe-se que pelo fato de a pessoa humana possuir essa liberdade para edificar sua existência é que se encontra a dignidade.

Por fim, após o término da Segunda Guerra Mundial, a ideia de dignidade da pessoa humana começou a ser estudada sob o prisma jurídico. Com o advento do pós-positivismo buscou-se reconciliar o direito e a ética, de modo a atribuir caráter normativo aos princípios jurídicos.

Infere-se, ao analisar a dignidade da pessoa humana sob os aspectos ora abordados até chegar ao direito, que esta adquire status de princípio jurídico, isso porque fora positivada no ordenamento jurídico brasileiro (inclusão expressa em texto normativo), tornando-se notório o avanço da constitucional ao normatizar tal princípio como fundamento do Estado Democrático de Direito, elencando-o no artigo $1^{\circ}$, III, da Constituição da República Federativa Brasileira.

Para Rizzatto Nunes, a dignidade "é o ultimo arcabouço da guarida dos direitos individuais e o primeiro fundamento de todo sistema constitucional" (2010, p. 78). Isso porque o Estado deve garanti-lo, posto se caracterizar como fundamento, e ao mesmo tempo poder limitar o direito e outras normas fundamentais. Por conseguinte, no âmbito jurídico, a dignidade como valor intrínseco da pessoa determina seja ela respeitada. $\mathrm{E}$, se submetido a ele, desenvolve outros direitos fundamentais como o direito à vida, à igualdade, à integridade física, à 
integridade psíquica, à liberdade e outros.

Conclui-se, pois, pelo dever de o Estado assegurar o princípio da dignidade da pessoa humana, e fomentar condições que proporcionem o respeito ao indivíduo. Ou seja, o direito à dignidade está relacionado à obrigação de ver viabilizado um mínimo existencial, exemplo disso é a imprescindibilidade do fornecimento dos serviços essenciais, para que os indivíduos possam usufruir de uma vida digna, característica essa inerente ao ser humano.

\subsection{A ideia da dignidade humana e a teoria do mínimo existencial}

Com fundamento na ideia de dignidade da pessoa humana, busca-se analisar a Teoria do mínimo existencial. A Constituição da República Federativa Brasileira não proclamou tal direito de forma expressa, todavia, ao assegurar os direitos sociais em seu artigo $6^{\circ}$, acaba por tratá-lo genericamente. Isso porque não há como falar em dignidade se os direitos sociais não forem respeitados, ou seja, "se esse mínimo não estiver garantido e implementado concretamente na vida das pessoas" (NUNES, 2010, p. 79).

Jürgen Habermans trata de cinco status de direitos fundamentais, sendo o quinto: "Direitos fundamentais a condições de vida garantidas social, técnica e ecologicamente, na medida em que isso for necessário para o aproveitamento, em igualdade de chance, dos direitos elencados de (1) até (4)" (2012, p.160). Aclarando, esse direito a condições de vida deve 
ser assegurado de forma que garanta a todos os direitos de: "iguais liberdades"; "status de um membro numa associação"; "possibilidade de postulação judicial [...] e da proteção jurídica individual"; "à participação, em igualdades de chances [...] exercitam sua autonomia política" (HABERMANS, 2012, p.159).

Arespeito da extensão do mínimo existencial, este abrange todos os direitos, ainda que originalmente não fundamental, considerando-se sua dimensão essencial, inalienável e existencial (TORRES, 2009, p.13).

Em suma, o direito ao mínimo existencial vincula todo ordenamento jurídico, e seu conceito é adstrito ao de dignidade, sendo necessária a prestação de um mínimo, do necessário, do essencial para se viver com dignidade.

A suspensão do fornecimento de energia elétrica aparece em oposição à idealização da teoria do mínimo existencial, pois não está sendo garantida pelo Estado a prestação de um mínimo para as famílias que, sem condições de arcar com despesas tão importantes, deparam-se nessa situação e não conseguem viver dignamente; fica, pois, prejudicado o cidadão, devido ao caráter de imprescindibilidade desse bem, além de ver sua honra atingida perante sua comunidade.

Em 2007, com o Agravo de Instrumento no 564.035/SP, a relatora ministra Cármen Lúcia definiu o mínimo existencial como conjunto de direitos fundamentais, indo além de condições materiais mínimas de existência:

O mínimo existencial afirma o conjunto de direitos fundamentais sem os quais a dignidade 
da pessoa humana é confiscada. E não se há de admitir ser esse princípio mito jurídico ou ilusão da civilização, mas dado constitucional de cumprimento incontornável, que encarece o valor de humanidade que todo ser humano ostenta desde o nascimento e que se impõe ao respeito de todos. (grifo próprio) (STF - AI: 564035 SP , Relator: Min. CÁRMEN LÚCIA, Data de Julgamento: 30/04/2007, Data de Publicação: DJ 15/05/2007 PP-00041).

Assim, permite-se concluir pela relação do mínimo existencial e a dignidade da pessoa humana, pois esse direito garantidor do conjunto de direitos fundamentais efetivas e assegura a dignidade da pessoa humana, sendo dever do Estado e da sociedade afirmar o mínimo de dignidade.

Por fim, infere-se ser um princípio garantidor do outro (dignidade da pessoa humana e mínimo existencial), já que a efetivação daquele está concatenado com o fato de ter proporcionado condições mínimas de vivência aos cidadãos. A paralisação da provisão de infraestrutura básica, como energia elétrica, àqueles que, por viverem precariamente, não possuem condições de adimplir, afronta, obviamente, a dignidade da pessoa humana.

\section{OS SERVIÇOS PÚBLICOS ESSENCIAIS À LUZ DO PRINCÍPIO DA CONTINUIDADE}

O fornecimento de energia elétrica é serviço público 
essencial devido a sua própria natureza, não podendo negar a indispensabilidade da utilização desse bem pela coletividade, bem como esse caráter é realçado por força de lei, exposto no artigo 10, inciso I, da Lei $\mathrm{n}^{\circ}$ 7.783, de 1989. Além disso, o artigo 170 da CRFB prevê os sustentáculos pelos quais o Estado deve conduzir sua economia, com a finalidade de assegurar a todos existência digna, dentre eles a defesa do consumidor.

Logo, é dever do Estado prestar de forma adequada e eficiente os serviços públicos, com escopo de atender às necessidades essenciais da coletividade, haja vista estes serem meios de efetivar os princípios fundamentais e sociais. Frisa-se, portanto, a importante relação entre a distribuição e consumo da energia elétrica e a concretização dos direitos fundamentais e, então, do princípio da dignidade da pessoa humana.

O órgão regulador da Agência Nacional de Energia Elétrica (ANATEL), em sua página oficial, aponta como missão proporcionar condições favoráveis de desenvolvimento ao mercado de energia elétrica com equilíbrio entre os agentes e em beneficio da sociedade ${ }^{2}$. No que diz respeito à suspensão do fornecimento de energia elétrica, em consonância ao disposto no já apreciado artigo $6^{\circ}, \S 3^{\circ}$ da Lei ${ }^{\circ} 8.987$, de 1995 , bem como a satisfação dos princípios caracterizadores do serviço adequado, estabelece o artigo 140, $\S \S 1^{\circ}$ e $3^{\circ}$ da Resolução n ${ }^{\circ} 414$, de 2010 da ANEEL:

$\S 1^{\circ}$ Serviço adequado é o que satisfaz as condições de regularidade, continuidade, eficiên-

$2 \quad$ ANEEL, site da Agência Nacional de Energia Elétrica. Disponível em <http://www. aneel.gov.br/area.cfm?idArea=635\&idPerfil=8 >.Acesso em 12/3/2013. 
cia, segurança, atualidade, generalidade, cortesia na sua prestação e modicidade das tarifas. [...] $\S 3^{\circ}$ Não se caracteriza como descontinuidade do serviço, observado o disposto no Capítulo XIV, a sua interrupção: [...]

II - após prévia notificação, por razões de ordem técnica ou de segurança em instalações de unidade consumidora, ou pelo inadimplemento do consumidor, considerado o interesse da coletividade.

Nota-se ser a prévia notificação requisito essencial para não caracterizar a descontinuidade, conforme a unanimidade dos precedentes judiciais. Ademais, depreende-se, portanto, não ser absoluto o princípio da continuidade. Entretanto, ainda que expressa a autorização da suspensão do fornecimento desse serviço, não pôs fim ao debate de sua (in)constitucionalidade, levantando diversos questionamentos como, por exemplo, quanto à possibilidade de uma simples resolução infringir princípio fundamental da Carta Magna.

Ademais, no inciso V do artigo 170 da Carta Maior, a defesa do consumidor é concebida como base principiológica da ordem econômica. Isso significa que, ao elencar a defesa do consumidor como fundamento da ordem econômica, esta deve sempre ser observada com o escopo de assegurar a todos existência digna.

De igual modo, o artigo 22 do Código de Defesa do Consumidor também definiu como contínuos os serviços públicos essenciais, não estabelecendo nenhuma exceção. Posto isso, o serviço público essencial deve se desenvolver de forma regular, sem interrupções. Nota-se não ter sido ao acaso o fato de 
o legislador pontuar, no artigo 10 da Lei n ${ }^{\circ} 7.783$, de 1989, como contínuo tais serviços, permitindo inferir a impossibilidade de assegurar existência digna à pessoa humana na hipótese de haver interrupção do fornecimento do serviço essencial como a energia elétrica.

Outrossim, nos contratos de concessão de serviço público essencial, aqui exemplificado pela energia elétrica, de um lado permanece a concessionária, monopolizadora da prestação e a visar lucros. De outro, encontram-se os consumidores, usuários do fornecimento de energia elétrica, bem este essencial, com o dever de ser prestado em consonância ao princípio da continuidade, a todos os indivíduos, por serem dependentes desse bem, fornecido em busca de uma existência digna.

\section{A SUSPENSÃO DO FORNECIMENTO DE ENERGIA ELÉTRICA ANTE O PRINCÍPIO DA DIGNIDADE DA PESSOA HUMANA}

\subsection{A inconstitucionalidade da suspensão do fornecimento de energia elétrica quando da inadimplência dos hipossuficientes}

A tutela ao consumidor justifica-se devido à sua vulnerabilidade, em busca de um equilíbrio entre as partes, bem como harmonização nos interesses. Para tanto, é necessária a intervenção do Estado, a fim de proteger o consumidor e garantir a igualdade na relação consumerista.

É inegável que uma parcela da população brasileira 
vive em estado de miserabilidade, no limite da sobrevivência biológica, muitas vezes com vários filhos, desempregada, ou recebendo apenas benefício assistencial, e, ainda, precisando arcar com tarifas de água e energia elétrica, bens estes essenciais e de obrigação do Poder Público prestá-los, para que seja assegurada uma vida digna.

Todos os consumidores, conforme já explanado, são considerados vulneráveis. Entretanto, há um grupo de pessoas que, além de revestido por essa vulnerabilidade, é hipossuficiente, ainda mais exposto numa relação consumerista, podendo ser chamado de hipervulnerável.

Os hipervulneráveis envolvem um grupo de pessoas que necessitam de maior proteção, indivíduos mais fragilizados. Claudia Lima Marques ensina que essa vulnerabilidade da pessoa física pode se dar em relação à idade, em situação de doença ou ainda por necessidades especiais (2010, p.199). Ou seja, são consumidores mais expostos ao modo como a concessionária desempenha seu fornecimento do serviço público, em razão de sua especial condição, a exemplo dos idosos, crianças, doentes, deficientes físicos e mentais, analfabetos e semi-analfabetos, bem como os que vivem em estado de miserabilidade, pessoas que de alguma forma necessitam de proteção especial.

É indubitável a necessidade de um tratamento diferenciado entre os hipervulneráveis, ainda que esse aspecto seja passageiro, e aqueles consumidores comuns. O ministro Herman Benjamin, ao julgar o recurso especial 586316/MG, entendeu que essa minoria carece de maior proteção, pelo fato de se encontrar em estado de miserabilidade, ou, outro fator configurador de sua 
hipossuficiência, ser este indivíduo menos cidadão:

[...] 18. Ao Estado Social importam não apenas os vulneráveis, mas sobretudo os hipervulneráveis, pois são esses que, exatamente por serem minoritários e amiúde discriminados ou ignorados, mais sofrem com a massificação do consumo e a "pasteurização" das diferenças que caracterizam e enriquecem a sociedade moderna. 19. Ser diferente ou minoria, por doença ou qualquer outra razão, não é ser menos consumidor, nem menos cidadão, tampouco merecer direitos de segunda classe ou proteção apenas retórica do legislador. (STJ - REsp: $586316 \mathrm{MG}$ 2003/0161208-5, Relator: Ministro HERMAN BENJAMIN, Data de Julgamento: 17/04/2007, T2 - SEGUNDA TURMA, Data de Publicação: DJe 19/03/2009)

O Estado deve garantir um tratamento isonômico, e, para concretização do princípio da dignidade da pessoa humana, é necessário que se assegure um mínimo vital para existência do indivíduo, sendo este o destinatário final das iniciativas públicas.

Assim, aqueles que não podem adimplir com a conta de energia em razão de viverem no limite da sua sobrevivência, de forma miserável, ao se depararem com a suspensão do fornecimento desse serviço essencial passam a ter condições precárias de vida, o qual, de certo, afronta a dignidade da pessoa humana. Indaga-se, pois: pode o direito ao crédito da concessionária sobrepor-se à dignidade da pessoa humana, quando inadimplente, por encontrar-se em estado de miserabilidade? 
Destarte, o STJ julgou como ilegal a suspensão do fornecimento de energia elétrica a pessoas hipervulneráveis, por atentar contra a dignidade da pessoa humana e outros direitos fundamentais. É o caso do recurso especial no $1.162 .946 / \mathrm{MG}$, de relatoria do ministro Sergio Kukina, em que o Ministério Público de Minas Gerais ajuizou ação civil pública visando à condenação da concessionária, consistente na proibição de interromper o fornecimento do serviço à pessoa carente de recursos financeiros, diagnosticados com enfermidade grave e dependente de equipamento médico de alto consumo de energia.

A paciente-consumidora é hipossuficiente economicamente e depende da utilização de equipamento elétrico de alto consumo para sobrevivência, posto ser portadora de doença pulmonar obstrutiva crônica grave e ter complicações cardiovasculares, elevando o valor da conta acima de 200,00 (duzentos reais). Ocorre que a interessada recebe benefício do sistema previdenciário federal no valor de R\$ 175,00 (cento e setenta e cinco reais), comprometendo sua capacidade econômico-financeira.

No voto, entende o ministro que o Ministério Público detém legitimidade ativa ad causam para propor ação civil pública, objetivando a proteção de direito à saúde de pessoa hipossuficiente, fazendo subsistir a decisão agravada. Ementa in verbis:

ADMINISTRATIVO. PROCESSUAL CIVIL. AGRAVO REGIMENTAL. AÇÃO CIVIL PÚBLICA. DIREITO À SAÚDE. DIGNIDADE DA PESSOA HUMANA. PROTEÇÃO DE DIREITOS FUNDAMENTAIS E INDISPONÍ- 
VEIS. LEGITIMIDADE ATIVA AD CAUSAM DO MINISTÉRIO PÚBLICO. PRECEDENTES. 1. O Ministério Público ajuizou ação civil pública visando à condenação da concessionária de energia elétrica à obrigação de não fazer, consistente na proibição de interromper o fornecimento do serviço à pessoa carente de recursos financeiros, diagnosticada com enfermidade grave e que depende, para sobreviver, da utilização doméstica de equipamento médico com alto consumo de energia. 2. Conforme jurisprudência deste Superior Tribunal de Justiça, o Ministério Público detém legitimidade ativa ad causam para propor ação civil pública, objetivando a proteção do direito à saúde de pessoa hipossuficiente, porquanto se trata de direito fundamental e indisponível, cuja relevância interessa à toda sociedade. 3. Agravo regimental a que se nega provimento.

(STJ - AgRg no REsp: 1162946 MG 2009/0208055-8, Relator: Ministro SÉRGIO KUKINA, Data de Julgamento: 04/06/2013, T1 - PRIMEIRA TURMA, Data de Publicação: DJe 07/06/2013)

Outro precedente pode ser citado, como o recurso especial $n^{\circ}$ 635.871/SP, de relatoria do ministro Luiz Fux, no qual ficou entendido que a ótica, a se analisar o corte de serviços essenciais, deve ser outra, "em primeiro lugar, distinguir entre o inadimplemento perpetrado por uma pessoa jurídica portentosa e o de uma pessoa física que está vivendo no limite da sobrevivência biológica". Buscando, desse modo, um tratamento diferenciado da pessoa física em estado de miserabilidade. Além disso, ressaltou que, ao possibilitar a lei de concessões, o corte, 
segundo a justificativa do interesse da coletividade, autorizou impedir a suspensão da energia a "uma pessoa que não possui condições financeiras para pagar contas de luz de valor módico, máxime quando a concessionária tem os meios jurídicos legais da ação de cobrança".

Ressalta, ainda, que "a responsabilidade patrimonial no direito brasileiro incide sobre o patrimônio do devedor e, neste caso, está incidindo sobre a própria pessoa". Alega não poder fazer uma aplicação da legislação infraconstitucional sem passar pelos princípios constitucionais, sobressaindo-se a dignidade da pessoa humana. Por fim, conclui:

Com tais fundamentos, e também outros que seria desnecessários alinhar, sou radicalmente contra o corte no fornecimento de serviços essenciais - água e energia elétrica - de pessoa física em situação de miserabilidade e absolutamente favorável ao corte de pessoa jurídica portentosa, que pode pagar e protela a prestação de sua obrigação, aproveitando-se dos meios judiciais cabíveis. (STJ - Resp. 635.871/SP, Relator: Ministro LUIZ FUX, Data de Julgamento: 18/05/2004, T1 - PRIMEIRA TURMA)

É exatamente essa linha de pensamento o entendimento do presente estudo. De fato, o usuário possui obrigações para com a empresa fornecedora do serviço, todavia, trata-se aqui de consumidor hipervulnerável, tendo o Estado a obrigação de garantir um mínimo vital. A dignidade da pessoa humana é um bem maior; não pode ser sacrificada em face do direito de crédito. 
Nesse diapasão, é importante que o Estado ofereça políticas públicas assistenciais, com o apoio da sociedade, a fim de proporcionar melhor qualidade de vida, resguardando a dignidade e proporcionando a isonomia. A tarifa social para baixa renda é exemplo de benefício em favor de grupo hipossuficiente. A Companhia de Energia Elétrica do Estado do Tocantins (CELTINS), em seu sítio eletrônico ${ }^{3}$, explica que essa tarifa de Energia Elétrica é um benefício criado pelo Governo Federal que concede descontos na conta de energia elétrica às famílias de baixa renda.

Mas, além disso, é importante destacar, conforme noticiado na própria página eletrônica da Celtins, que "quase $50 \%$ do que os consumidores pagam pela energia elétrica que consomem corresponde a tributos. O tributo de maior peso nessa equação é o ICMS que pode, na ponta do lápis, chegar a até $42 \%$ do valor da energia" 4 . Diante dessas considerações, é relevante lembrar o papel do Estado na sociedade, tendo surgido para dirimir os conflitos, reconhecer e garantir os direitos dos indivíduos, com o objetivo de construir uma sociedade livre, justa e solidária; garantir o desenvolvimento nacional; erradicar a pobreza e a marginalização e reduzir as desigualdades sociais e regionais; promover o bem de todos.

Logo, é necessário que o governo elabore planos, a fim de assistir os cidadãos, para a garantia de uma vida digna e em

3 CELTINS, site da Companhia de Energia Elétrica do Estado do Tocantins. Disponível em <http://www.celtins.com.br/sua-conta/tarifa-social-para-baixa-renda/>. Acesso em 13 mar. 2013.

4 CELTINS, site da Companhia de Energia Elétrica do Estado do Tocantins. Disponível em <http://www.celtins.com.br/imprensa/tributacao-de-energia-luz-no-fim-do-tunel/> Acesso em 13 mar. 2013. 
busca de oferecer subsistência mínima básica. E mais do que isso, de forma paralela, deve trabalhar pelo povo, com o propósito de geração de renda e emprego, buscando atingir erradicar a pobreza e reduzir as desigualdades sociais, assegurando a dignidade e proporcionando condições para o indivíduo adimplir seus débitos.

A energia alcançou proeminente posição nos países em desenvolvimento. A busca pela redução da pobreza e inclusão social está vinculada à necessidade de ampliação do recebimento desse serviço essencial. A China, por exemplo, tem uma maioria da população em áreas rurais,

O Estado como proprietário das empresas de energia implementou um conjunto de políticas direcionadas ao estimulo do desenvolvimento rural via acesso à energia elétrica [...] O Programa entrelaça questões de redução de pobreza com conservação do meio ambiente e no desenvolvimento de fontes renováveis de energia. (PEREIRA, 2011, p.143)

Logo, o meio encontrado para atender de forma mais eficaz a população chinesa foram as fontes renováveis de energia, assim como diversos programas surgidos, como: Brightness Program - projeto direcionado à redução da pobreza -, investindo em energia solar e eólica "com o objetivo de aprimorar as condições de vida e de trabalho das populações localizadas em áreas remotas por meio de fontes descentralizadas de energia." (PEREIRA, pp.144-145). Outro programa é o State Development Planning Commission (SDPC) ou National Development and Reform 
Commission (NDRC), objetivando atender às necessidades das concessionárias públicas e das residências não eletrificadas: na primeira etapa, por estações de geração de energia elétrica por meio de painel fotovoltaico; na segunda, por pequenas centrais hidroelétricas (PEREIRA, pp. 145-146).

Por fim, conclui o pesquisador que

As relações entre energia e saúdes são complexas, entretanto dois aspectos devem ser citados, cabendo destacar os melhoramentos nos domicílios por meio do fornecimento de energia elétrica de forma regular e da disponibilidade de eletrodomésticos utilizados com fins paralelos de higiene, na preparação das refeições, e de refrigeração dos alimentos. Conjuntamente, sob a ótica pública, medicamentos podem ser mantidos resfriados. [...] A China promoveu um acelerado progresso na melhoria do padrão de vida das pessoas [...] A eletrificação rural na China tem sido um caso de sucesso, especialmente considerando o nível de desenvolvimento econômico, mesmo ainda com rápido crescimento econômico, e sendo subsidiado pelo governo [...] A eletrificação precisa ser direcionada e acompanhada por uma séria de ações econômicas, sociais e ambientais, no sentido de promover programas associados a transportes, atividades agrícolas, crédito, educação, saúde, considerando tais igualmente importantes. (PEREIRA, p. 151-153)

Os exemplos mostram-se pertinentes à análise da possibilidade de o Estado Brasileiro desenvolver outras políticas públicas de produção e distribuição de energia elétrica. Além 
disso, importa perceber, no Brasil, a produção de energia por meio de hidrelétricas, meio oneroso e que explora de forma drástica as bacias hidrográficas, ocorrendo perda de habitat, fauna, flora, e outros prejuízos.

Ocorre que, mesmo com o Estado assistencialista empregando políticas públicas, se o consumidor em estado de miserabilidade não conseguir arcar com a sua obrigação de pagar a tarifa de energia elétrica, não pode ter suspenso seu fornecimento nem afrontada sua dignidade. A concessionária, por ser hiperssuficiente, deve entrar com uma ação judicial de cobrança, podendo até mesmo, em liminar, pedir a suspensão da prestação do serviço essencial, e, tendo autorização judicial, efetuar o corte.

Outro mecanismo de ver garantida a continuidade do fornecimento de energia elétrica é por meio de uma ação civil pública - instrumento processual para a defesa de interesses difusos, coletivos e individuais homogêneos -, ajuizada pelo Ministério Público, com vistas à condenação das concessionárias de energia elétrica à obrigação de não fazer, consistente na proibição de suspender o fornecimento de tal serviço público essencial à pessoa hipervulnerável, ou seja, em estado de miserabilidade, ou dependente de utilização de aparelho elétricomédico para sua sobrevivência, por exemplo. É nesse sentido o precedente já analisado: AgRg no REsp: 1162946/MG.

Nesse caso, por estar o fornecedor em superioridade, levando em consideração o aspecto econômico, técnico, jurídico e administrativo, em relação ao consumidor, mormente a um consumidor hipervulnerável, e pelo caráter de essencialidade, 
pelo qual é revestido o serviço de energia elétrica, deve o Poder Público, junto com a concessionária, suportar o ônus.

$\mathrm{O}$ direito à dignidade está relacionado a usufruir de condições mínimas de sobrevivência e vida saudável e, ao suspender o fornecimento de energia elétrica de pessoa hipervulnerável por sua inadimplência, evidente é o confronto à dignidade da pessoa humana, havendo inversão da ordem constitucional, pois estaria proporcionando superior guarida ao direito de crédito da concessionária em detrimento dos direitos fundamentais. A responsabilidade patrimonial não pode transcender o patrimônio do devedor e incidir sobre a própria pessoa, sendo deplorável considerar o direito de crédito da concessionária em detrimento da dignidade da pessoa humana.

\section{CONSIDERAÇÕES FINAIS}

O princípio da dignidade da pessoa humana é direito fundamental ao desenvolvimento do Estado Democrático de Direito, garantido constitucionalmente; alicerce de todo ordenamento jurídico constitucional; e o último refúgio dos direitos individuais. Importante frisar que, por ser qualidade intrínseca, esta não é concedida pelo ordenamento jurídico, pois a dignidade é inerente a todo ser humano.

Conjuntamente, o Código de Defesa do consumidor surge com o fito de atender a uma necessidade da Constituição da República Federativa Brasileira, sendo a defesa do consumidor concebida como base principiológica da ordem econômica. Logo, busca estabelecer um sistema protetivo para desenvolver 
o equilíbrio entre os agentes.

Pondera-se, ainda, que o caráter de essencialidade cinge o fornecimento de serviço público, é o caso da energia elétrica, sendo, na sociedade moderna, inegável sua indispensabilidade para uma vida digna e saudável, tendo sido elencada no ordenamento jurídico pátrio como um dos serviços essenciais.

Nesse diapasão, o presente estudo permitiu inferir que a concretização do direito à dignidade vincula-se ao usufruto de condições mínimas de sobrevivência e vida saudável, portanto, não é possível suspender o serviço de energia elétrica sem que haja afronta aos fundamentos constitucionais.

A respeito do entendimento do Superior Tribunal Federal, é possível perceber o seu desvelo em discernir no caso concreto a pessoa física miserável. Isso porque os seus julgados assentaram no sentido de ser legítima a suspensão do fornecimento de energia elétrica por inadimplemento do consumidor após aviso prévio feito ao inadimplente. Todavia, há precedentes que determinaram pela distinção entre o inadimplemento perpetrado por uma pessoa jurídica portentosa e o de uma pessoa física cuja sua vivência se dá no limite da sobrevivência biológica, decidindo, ao final, pela ilegitimidade da interrupção de serviço público essencial à família em situação de miserabilidade absoluta, em respeito à dignidade da pessoa humana, devendo a concessionária, nesse caso, buscar o cumprimento da obrigação por via judicial.

Assim, ao registrar a não garantia a esse grupo de cidadãos hipervulnerável, de um mínimo existencial e, já considerando a violação da própria condição de ser humano quando não se 
veem atendidas as necessidades vitais, é que se conclui pela inconstitucionalidade do corte de energia elétrica.

$\mathrm{O}$ direito à dignidade está relacionado a usufruir de condições mínimas de sobrevivência e vida saudável e, ao suspender o fornecimento de energia elétrica de pessoa hipervulnerável por sua inadimplência, evidente é o confronto à dignidade. É por isso que a responsabilidade patrimonial não pode transcender o patrimônio do devedor e incidir sobre a própria pessoa, uma vez que, considerar o direito de crédito da concessionária em detrimento da dignidade da pessoa humana, é lastimável. De fato, o usuário tem obrigações a serem cumpridas diante da empresa fornecedora do serviço, entretanto, encontrase aqui consumidor hipervulnerável, tendo o Estado obrigação de garantir um mínimo vital. A dignidade da pessoa humana é um bem maior; não pode ser sacrificada em face do direito de crédito.

Nesse diapasão, é imprescindível o oferecimento de políticas públicas por parte do Estado, com apoio da sociedade, a fim de assegurar a isonomia, sendo necessária a elaboração pelo governo de planos que possam assistir aos cidadãos, para a garantia de uma vida digna e em busca de oferecer subsistência mínima básica. E mais do que isso, de forma paralela, deve o Poder Público trabalhar pelo povo, com o propósito de geração de renda e emprego, para erradicar a pobreza e reduzir as desigualdades sociais, assegurando a dignidade e proporcionando condições para o indivíduo adimplir seus débitos. 


\section{REFERÊNCIAS}

ALEXY, Robert. Teoria dos direitos fundamentais. 2. ed. São Paulo: Malheiros, 2011.

ANDRADE, André Gustavo Corrêa de. O princípio fundamental da dignidade humana e sua concretização judicial. Disponível em: < http://www.tjrj.jus.br/institucional/ dir_gerais/dgcon/pdf/artigos/direi_const/o_principio_ fundamental_da_dignidade_humana_e_sua_concretizacao_ judicial.pdf $>$. Acesso em: 18 dez. 2013.

ANEEL. Agência nacional de energia elétrica. Disponível em: $<$ http://www.aneel.gov.br/area.cfm?idArea $=635 \&$ idPerfil $=8>$. Acesso em: 12 mar. 2013, às 10h50.

Resolução normativa no $\mathbf{n}^{\mathbf{4}} \mathbf{4 1}$, de 9 de setembro de 2010. Estabelece as Condições Gerais de Fornecimento de Energia Elétrica de forma atualizada e consolidada. Disponível em: $<$ http://www.aneel.gov.br/cedoc/ren2010414.pdf $>$. Acesso em: 9 dez. 2013.

BRASIL. Constituição da República Federativa do Brasil de 1988, de 5 de outubro de 1988. Diário Oficial da União, Brasília, DF, 5 outubro 1988. Disponível em: <http://www.planalto.gov. br/ccivil_03/constituicao/constituicao24.htm>. Acesso em: 12 mar. 2013.

. Lei $\mathbf{n}^{\mathbf{0}} \mathbf{7 . 7 8 3 / 8 8}$, de 28 de junho de 1989. Dispõe sobre o exercício do direito de greve, define as atividades essenciais, 
regula o atendimento das necessidades inadiáveis da comunidade, e dá outras providências. Conversão da Medida Provisória ${ }^{\circ}{ }^{59}$, de 1989. Diário Oficial da União, Brasília, 28 de junho de 1989; $168^{\circ}$ da independência e $101^{\circ}$ da República. Disponível em: $<$ http://www.planalto.gov.br/ccivil_03/leis/17783.htm>. Acesso em: 12 mar.

2013.

. Lei $\mathbf{n}^{\mathbf{0}} \mathbf{8 . 0 7 8}$, de 11 de Setembro de 1990. Dispõe sobre a proteção do consumidor e dá outras providências. Diário Oficial da União, Brasília, DF, 11 de Setembro de 1990. Disponível em: $<$ http://www.planalto.gov.br/ccivil_03/leis/18078.htm>. Acesso em: 12 mar. 2013.

BRASIL. Superior Tribunal de Justiça. Resp. 635.871/SP, Relator: Ministro LUIZ FUX. Data de Julgamento: 18/5/2004, T1 - PRIMEIRA TURMA.

- Superior Tribunal de Justiça. REsp: 586316 MG 2003/0161208-5. Relator: Ministro HERMAN BENJAMIN. Data de Julgamento: 17/04/2007. T2 - SEGUNDA TURMA. Data de Publicação: DJe 19/3/2009.

. Superior Tribunal de Justiça. AgRg no REsp: 1162946 MG 2009/0208055-8. Relator: Ministro SÉRGIO KUKINA. Data de Julgamento: 4/6/2013. T1 - PRIMEIRA TURMA. Data de Publicação: DJe 7/6/2013.

. Superior Tribunal de Justiça. Resp. 635.871/SP. Relator: Ministro LUIZ FUX. Data de Julgamento: 18/05/2004. T1 - 
PRIMEIRA TURMA.

CELTINS. Companhia de Energia Elétrica do Estado do Tocantins. Disponível em: <http://www.celtins.com.br/suaconta/tarifa-social-para-baixa-renda/ $>$. Acesso em: 13 mar. 2013.

- Companhia de Energia Elétrica do Estado do Tocantins. Disponível em: <http://www.celtins.com.br/suaconta/tarifa-social-para-baixa-renda/ $>$. Acesso em: 13 mar. 2013.

- Companhia de Energia Elétrica do Estado do Tocantins. Disponível em: <http://www.celtins.com.br/ imprensa/tributacao-de-energia-luz-no-fim-do-tunel/>. Acesso em: 13 mar. 2013.

HABERMAS, Jürgen. Direito e democracia: entre facticidade e validade, vol. I. 2 ed. Rio de Janeiro: Tempo Brasileiro, 2012.

KANT, Immanuel. Fundamentação da metafísica dos costumes. São Paulo: Discurso Editorial, Barcarolla, 2009.

MARQUES, Claudia Lima; BENJAMIN, Antônio Herman V.; MIRAGEM, Bruno. Comentários ao código de defesa do consumidor. 3. ed. rev., atual. e ampl. São Paulo: Editora Revista dos Tribunais, 2010.

MARTINS, Flademir Jerônimo Belinati. Dignidade da pessoa humana: princípio constitucional fundamental. Curitiba: Juruá, 2012. 
NUNES, Luiz Antônio Rizzato. Comentários ao código de defesa do consumidor. 6. ed. rev., atual e ampl. São Paulo: Saraiva, 2011. . Luiz Antônio Rizzato. O princípio constitucional da dignidade da pessoa humana: doutrina e jurisprudência. 3. ed. rev. e ampl. São Paulo: Saraiva, 2010.

PEREIRA, Marcio Giannini. Políticas públicas de eletrificação rural na superação da pobreza energética brasileira: estudo de caso da bacia do rio acre - Amazônia. Rio de Janeiro, 2011. Disponível em: http://www.ppe.ufrj.br/ppe/production/tesis/ mpereira.pdf. Acesso em: 9 mar. 2014.

SARLET, Ingo Wolfgang. Dignidade da pessoa humana e direitos fundamentais: na Constituição Federal de 1988. 9. ed. Porto Alegre: Livraria do Advogado Editora, 2011.

TORRES, Ricardo Lobo. O direito ao mínimo existencial. Rio de Janeiro: Renovar, 2009.

Recebido em: 30/06/2014

Aprovado em: 06/08/2014 